\title{
Study the Possibility of Using the Modified Asphalt Mixtures with Waste Plastic in High-Temperature Areas
}

\author{
Feras Al Adday ${ }^{1}$, Fatima Alsaleh ${ }^{2}$ \\ ${ }^{1}$ Middle East University, Amman, Jordan, falkhalil@meu.edu.jo \\ ${ }^{2}$ Department of Transportation Engineering, Faculty of Civil Engineering, University of Aleppo, Syria, \\ alsaleh-f@alepuniv.edu.sy
}

\begin{abstract}
Flexible road paving layers are subjected to mechanical stresses caused by traffic as well as thermal stresses resulting from climatic and environmental changes that lead to the appearance of deformations and cracks. Therefore, the Hot Mix Asphalt (HMA) must maintain a continuous and acceptable performance under the influence of the different conditions to which they are subject. Environmental and climatic conditions affecting the performance of asphalt mixtures include moisture, temperature and their interactions. As for the temperature, when the temperature rises, the asphalt mixtures soften and become softer and lead to rotting. Therefore, good paving design must take environmental and climatic changes into account.

This research aims to study the permanence of modified asphalt mixtures (MAM) with waste plastic (WP) under the influence of exposure to high temperature in addition to studying durability of HMA and MAM mixtures by immersing the samples with water at $80^{\circ} \mathrm{C}$ for variable time periods according to the following $(8,16,32,64$, and 128 hours) at $6 \%$ optimum content of WP. The volumetric and mechanical properties of HMA and MAM mixtures have been determined using different proportions of asphalt $(4.5 \%, 5 \%$, $5.5 \%, 6$ and $6.5 \%$ by total weight of mixtures). The optimum content was $5.5 \%$ by weight of asphalt. Various percentages of WP $(2 \%, 4 \%, 6 \%, 8 \%, 10$, and $12 \%$ of optimum asphalt content (OAC) are used to determine optimum content of WP that was found to be $6 \%$ of OAC. The outcomes show that the addition of WP has a significant positive influence on the properties of HMA.
\end{abstract}

Key words: Waste Plastic, High Temperature, Modified Asphalt.

\section{INTRODUCTION}

HMA is the most common kind for flexible pavements. Statistics show that there are about 4.33 million kilometers of paved highways in the United States (US), and most of these roads are paved with HMA, reaching more than $90 \%$ of the roads. [1]. HMA can be considered as a complex mix that comprise of three main components: asphalt, aggregate, and voids. Nonetheless, aggregates is primarily component in HMA and constitutes $97 \%$ of the total weight [2].

Recently, new techniques were adopted to produce new sources extracted from the recycling of some expired materials to decrease the undesirable effects of cumulative a WP and reduction the need of natural materials [3][4][5]. WP is a byproduct of consuming different bottles (drinking water, soft drinks, and yoghurt) and the plastic bags used for packing, catering, and vegetables. Plastic tools are prepared of Polyethylene Terepthalate (PET) and High-density Polyethylene (HDPE) [6].

The three interrelated elements, namely design, construction, and maintenance, constitute an economic and environmental strategy to maintain facilities. In such strategies used to construct highway pavement layers, the goal is to define a technique to develop the asphalt performance by preserving natural resources and reducing energy consumption and carbon dioxide emissions in addition to minimizing maintenance as it is one of the future obstacles to any project [7]. Additives can be added to asphalt mixtures in different ways, such as wet and dry method, and there are several types of them, such as industrial polymers (such as polypropylene, polypropylene, and polystyrene), recycled rubber, and WP [8][9].

One of the most important sources of plastic waste is the plastic industries for human consumption purposes in Jordan and many countries [10]. And for this important matter, the search for the use of such materials in the road industry has become an urgent engineering priority. HMA is chosen to ensure optimal performance under heavy loading conditions and severe weather conditions (lowest temperature or high temperature) during the service life of the road [11].

Several researchers have studied the possibility of adding WP to HMA and have obtained good results. Paul and Bhattacharya in 2015 prove that adding WP to aggregates during the mixing process decrease the water absorption and voids in addition to improving durability mixtures, and these mixtures can resist heavy traffic with better performance [12]. 
Feras Al Adday et al., International Journal of Emerging Trends in Engineering Research, 8(4), April 2020, 1090 - 1095

As stated by Chavan in 2013, WP from used grocery bags can be valuable in the production of MAM, this is done by increasing the resistance and performance of the surface layer as well as it also reduces the percentage of asphalt used in the mixture by $10 \%$ [13].

On the other hand, Ahmed uzzaman and other in 2013 determined that the WP can add up to $10 \%$ of asphalt content to HMA mixes, and also can add up to $7.5 \%$ of PVC to HMA mixes in a heater area from the viewpoint of stability, air voids, and toughness characteristics [14].

Another investigation achieved by Abu Abdo in 2017, he use WP as a modifier to HMA with $0,0.2,0.5$, and $1 \%$ of overall aggregates weight. Results shown that adding $0.2 \%$ WP would improve HMA performance. He has also revealed that adding 0.5\% WP would produce sustainable HMA [15]. Al-Humeidawi in 2014 examined the possibility of adding WP extracted from plastic bags in making of HMA mixture. He was stated that coat the aggregates with modified asphalt result in increased stability to rate equal to $10 \%$ and an increase of up to $9 \%$ in the value of indirect tensile strength related to control mixtures [16].

\section{RESEARCH GOALS}

Based on the previous reference study, the effect of high temperature levels on the performance of modified asphalt mixtures with WP has not been studied. Not surprisingly, this investigation targets to study the effect of continuous exposure to high temperatures on these mixtures. As is known, the submersion temperature of the Marshall samples in the water bath is $60^{\circ} \mathrm{C}$. In this paper, the degree of samples immersion will be $80^{\circ} \mathrm{C}$.

\section{METHODOLOGY}

Based on the environmental and climatic general conditions in Jordan. As a result of these harsh conditions in some seasons [17], the proportion of asphalt to the total weight of the asphalt mix is as follows: 4, 4.5, 5, 5.5, 6, and $6.5 \%$. The asphalt used had the specifications shown in the table1. The characteristics of natural aggregates are defined, L A abrasion value (ASTM C131 - 81) remained within the permitted limits, which were $27.14 \%$, It is less than satisfactory value (30\%) [18], and aggregates gradation in accordance with Jordanian specifications as showed in Table2.Specific gravity of aggregates were 2.6 for coarse, 2.61 for fine, and 2.70 for filler.

WP consists of a variety of consumed household bags collected from municipal waste. These bags are cut into small parts ranging from 1 to $3.6 \mathrm{~mm}$, specific gravity was 0.96 (ASTM D792). The shredded WP was added to the asphalt cement at temperature between 160 and $170{ }^{\circ} \mathrm{C}$, they were manually moved for a period of 20 to 30 seconds. This process resulted in a uniformity within 25 to 30 seconds. Changed proportions of WP as follows: $0 \%, 2 \%, 4 \%, 6 \%, 8 \%, 10 \%$ and
$12 \%$ which were replaced of OAC. MAM (asphalt-WP) and reference mixture were prepared, where WP added over the hot asphalt $\left(155^{\circ} \mathrm{C}\right)$.

The optimum modified asphalt-WP content were determined by calculating the mixtures' performance in relation to the Marshall Examination (ASTM D 1559-89), specimens' number were 21 . At the beginning of the study it had been prepared specimens test to determine OAC, specimen number also were 21. Figure 1 shows some of the samples tested.

To study the influence of high temperature levels on the performance of MAM with WP, the subsequent technique was used: 18 specimens of each category of mixtures were made (the total were 36 specimens HMA and MAM), and then placed in a water path to expose them to $80{ }^{\circ} \mathrm{C}$ According to the following schedule $0,8,16,32,64$, and 128 hours, these specimens where then removed and placed in a water bath of $60{ }^{\circ} \mathrm{C}$ for 24 hours, these specimens were then taken and tested directly, stability and flow were calculated. The Marshall specimens were compacted by using compaction procedure with 75 blows on the top and bottom face of the specimens at $140-145^{\circ} \mathrm{C}$.

Table 1: Asphalt specifications

\begin{tabular}{ccc}
\hline \multicolumn{3}{c}{$\begin{array}{c}\text { Asphalt specifications as obtained through } \\
\text { experiments }\end{array}$} \\
\hline Test & value & Method \\
\hline Ductility & $77 \mathrm{~cm}$ & ASTM D113 \\
\hline Penetration & $64 \mathrm{~mm}$ & ASTM D-5 \\
\hline Softening point & $51.45^{\circ} \mathrm{C}$ & ASTM D-36 \\
\hline Fire point & $314^{\circ} \mathrm{C}$ & AASHTO T48 \\
\hline Flash point & $286^{\circ} \mathrm{C}$ & AASHTO T48 \\
\hline Specific gravity & 1.03 & ASTM D-70 \\
\hline
\end{tabular}

Table 2: Aggregates Gradation Aggregate Gradation according to ASTM C131 $\%$ Percentage of passage Fine Coarse Aggregate Sieve opening Aggregate

\begin{tabular}{ccc}
\hline $\mathbf{2 5} \mathbf{~ m m}$ & 100 & 100 \\
\hline $\mathbf{1 9} \mathbf{~ m m}$ & 100 & 97.24 \\
\hline $\mathbf{1 2 . 5} \mathbf{~ m m}$ & 100 & 60.65 \\
\hline $\mathbf{9 . 5} \mathbf{~ m m}$ & 100 & 33.59 \\
\hline $\mathbf{\# 4}$ & 99 & 2.88 \\
\hline $\mathbf{\# 8}$ & 86 & 0.57 \\
\hline $\mathbf{1 6}$ & 50 & 0 \\
\hline $\mathbf{3 0}$ & 30 & 0 \\
\hline $\mathbf{\# 5 0}$ & 16 & 0 \\
\hline $\mathbf{7 5} \mathbf{m c})$ & 7 & 0 \\
\hline
\end{tabular}




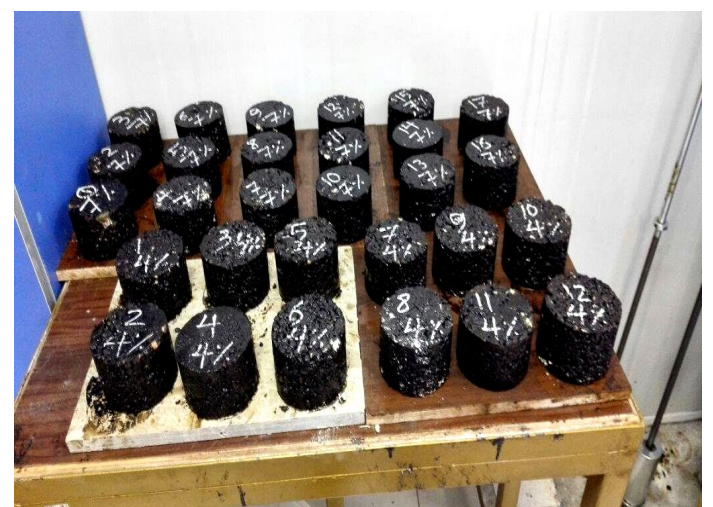

Figure 1: Marshall samples after molding

\section{RESULTS AND DISCUSSION}

\subsection{Determine the Percentage of PP}

The mechanical properties of MAM were calculated after adding WP into HMA mixes. The results of the tests are presented by Figures showing the relationship between the proportion of WP and each of the specific gravity, Marshall stability, air voids, voids in mineral aggregate (VMA), and flow.

As the WP content increases, the values of specific gravity gradually decreases, as shown in Fig. 2. This performance is attributable to the creation of minor crystal parts of the WP in the mix of HMA. This results in lower values of specific gravity compared to the aggregates.

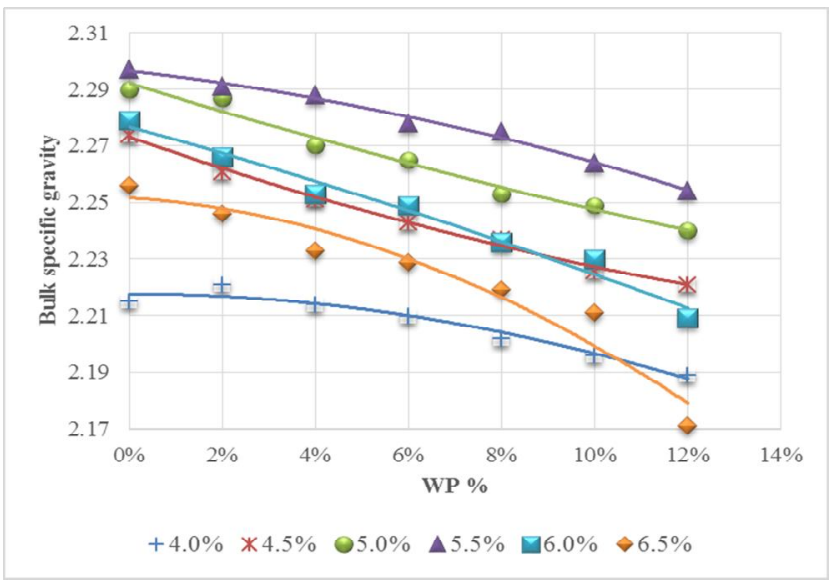

Figure 2: Variable proportions of versus bulk specific gravity

As presented in Fig. 2, increasing the percentage of WP leads to an increase in stability value until 6\% of WP and then it variations to a downward movement. The improved performance of these mixtures can be explained by the increase in the ratio of WP to the fact that the WP have greater adhesion between the aggregates in the mix. After that, any increase in WP leads to a decrease in the stability, this result is related to the formation of a stiffer blend made from a small crystal of WP particles.

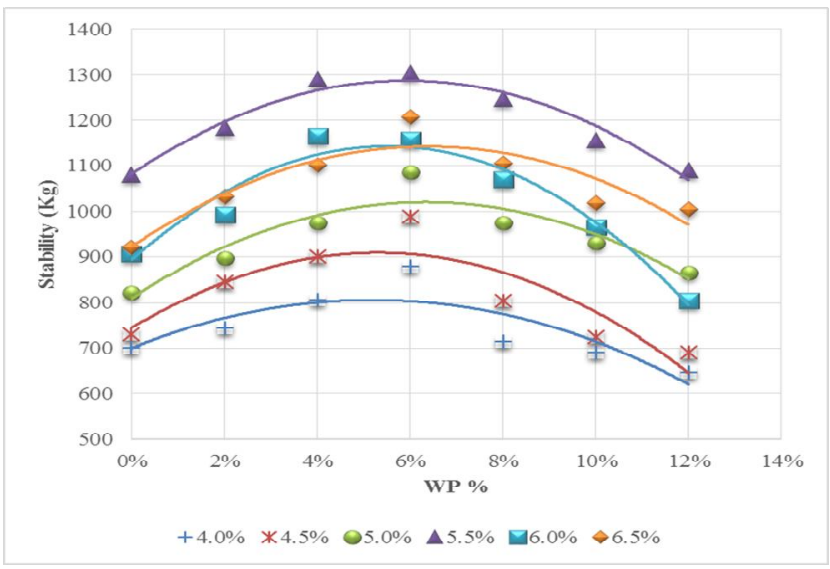

Figure 3: Variable proportions of WP versus Marshall stability

As showed in Fig. 4, an increase in the WP ratio leads to a gradual decrease in the flow until $6 \%$ of WP and then it variations to an increasing movement. As shown above, this performance may contribute to the creation of a stiffer blend. Nevertheless, the high value of the flow is accompanied by a low value for stability [16].

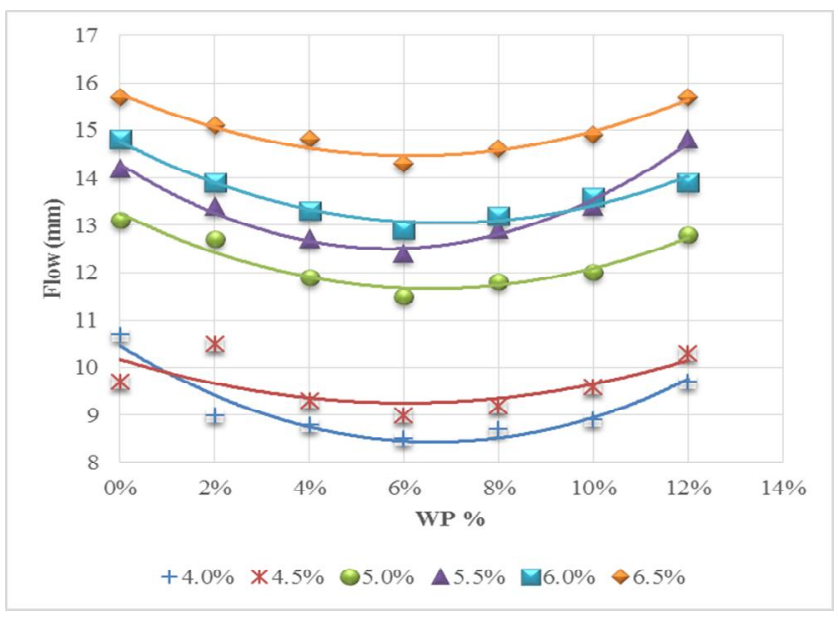

Figure 4: Variable proportions of WP versus Flow

As Fig. 5 demonstrations, increasing the WP ratio leads to additional air voids in HMA mix because of the chopped WP added in the mix. This performance is attributed to the two influences, the first of which is the increase in WP, which leads to the weakening of the compact capacity, and consequently, larger voids. The second is the formation of a stiffer crystal particles, which forms a larger surface area, thus requiring a greater asphalt during the mixing process of HMA, thus creating larger voids [19]. 
Feras Al Adday et al., International Journal of Emerging Trends in Engineering Research, 8(4), April 2020, 1090 - 1095

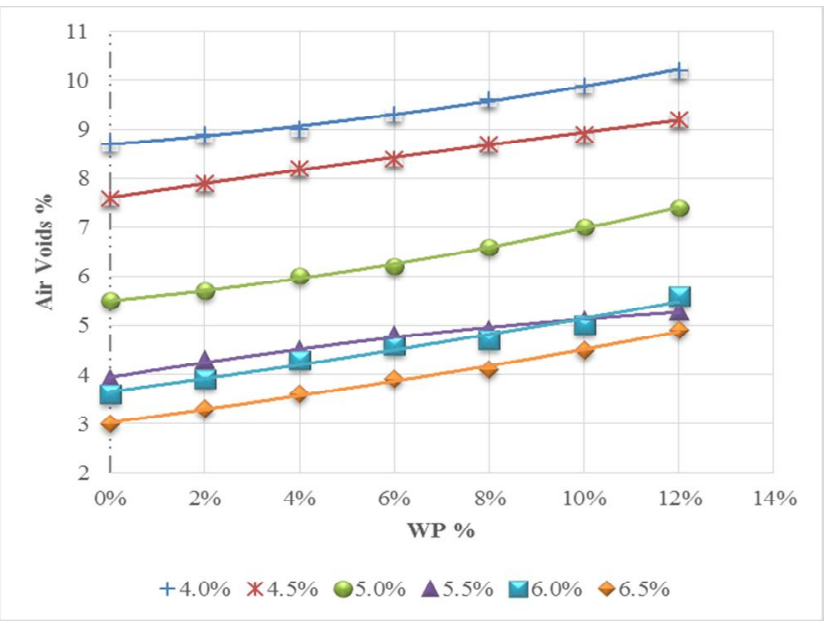

Figure 5: Variable proportions of WP versus air voids

As shown clearly from Fig 6, the increase in WP corresponds to an increase in VMA ratio. As is evident from this figure, the VMA ratio in MAM mixes are greater than those of the reference mixes for each asphalt content. The HMA durability is affected by the thickness of the asphalt film around the aggregates. In order to obtain a high durability, the percentage of VMA must be less [20].

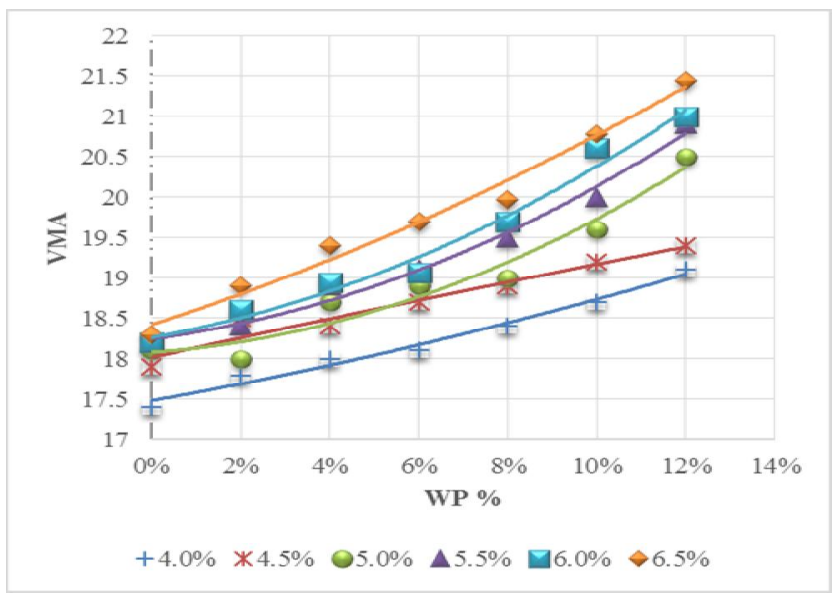

Figure 6: Variable proportions of WP versus VMA

According to determine maximum values of specific gravity and stability, as well the void ratio (4\%), the optimum WP proportion are 6 of asphalt weight. As the proportion of the total asphalt was also determined by $5.5 \%$ of the total weight of the Marshall sample according to the same experiments in which the WP proportion was determined. Consequently, it can be confirmed that the influence of $\mathrm{PW}$ on the mechanical properties is significant.

\subsection{Study of Durability of MAM and Reference Mixtures.}

Time duration of exposure to excess temperature $\left(80{ }^{\circ} \mathrm{C}\right)$ affects both reference and MAM with PW. However, the MAM exhibit greater durability when the period of exposure to high temperature increases, as shown in Figure 7 and 8.

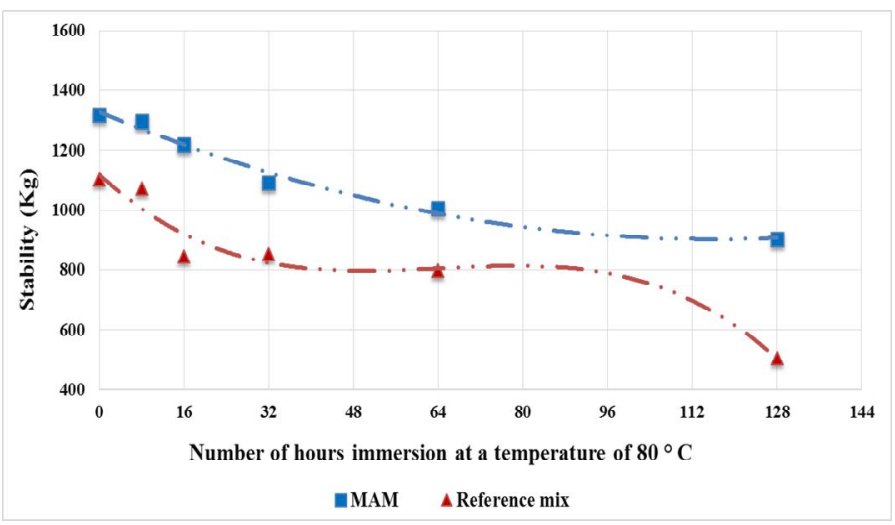

Figure 7: Stability VS number of hours at a high temperature

The durability of MAM decrease gradually with increasing hours of immersion with high temperatures. But reference mixtures start to decrease for up to 16 hours, after which the shape of the curve changes upward and then decreases dramatically at 32 hours of exposure to high temperature. The behavior of reference mixtures can be explained by the fact that the increase in temperature led to a decrease in the viscosity of the asphalt, so that the aggregate are repositioned as a result of the expansion of the asphalt and the aggregated, so the value of the stability decreases, and by increasing the time duration of exposure to high temperature, the oils and volatile substances in the asphalt begin to volatilize and evaporate, which leads to an asphalt hardening that gives higher stability than before. And with continued exposure to high temperatures, the stability values begin to decrease as a result of the oxidation of the asphalt surrounding the aggregate, and the action of water begins to appear slowly. It can be observed that the increase in durability of the MAM is approximately 79 percent higher than the reference mixture at 128 hours of exposure to high temperature.

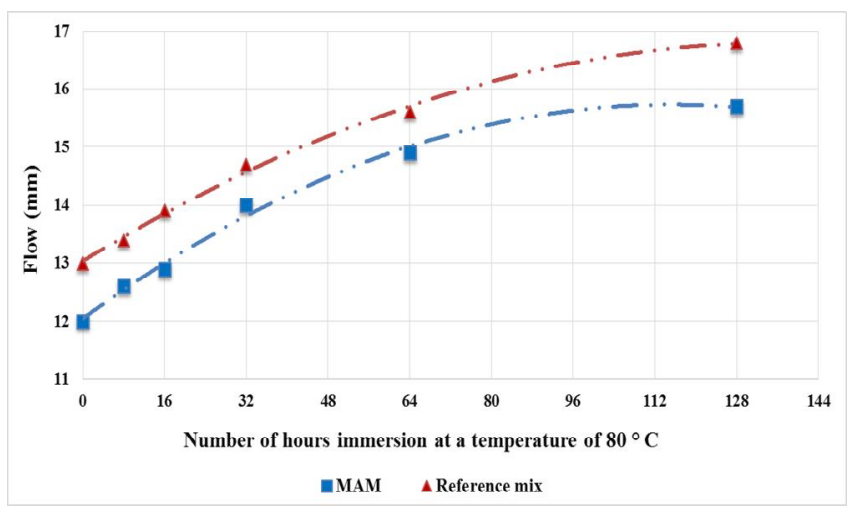

Figure 8: Stability VS number of hours at a high temperature 
Feras Al Adday et al., International Journal of Emerging Trends in Engineering Research, 8(4), April 2020, 1090 - 1095

From the above, it is clear that the use of WP as an additive for HMA mixes has reduced the flow values as shown in Figure 8, where flow for MAM is lower than HMA mixes. The addition of WP has improved the durability of these mixtures and their resistance to exposure to high temperature as shown in Figure 8, due to the improvement of the cohesion and adhesion properties of the asphalt, as the use of WP leads to the hardening of the asphalt.

\section{CONCLUSION}

It can be summarized the results of laboratory samples that have been prepared in accordance with the wet method (by adding WP to HMA) with the following:

1. The experiments carried out on the HMA showed that the OAC was $5.5 \%$ of the total weight of the asphalt mixtures.

2. The proportion of WP added to the asphalt was $6 \%$ of the weight of the added asphalt for the HMA.

3. Experiments have shown that the specific gravity decreases by increasing the proportion of WP. Conversely, the flow increases as the WP increases.

4. There is an inverse relationship between stability and flow. Increasing one leads to a decrease in the other.

5. The results show the divergence of the durability curves. The stability values for the HMA at 128 hours are lower than MAM by $79 \% \%$. The use of WP helped to increase the resistance of these mixtures to the effect of high temperature and thus better durability.

\section{ACKNOWLEDGMENT.}

The authors are grateful to the Middle East University, Amman, Jordan for the financial support granted to cover the publication fee of this research article.

\section{REFERENCES}

1. Ali Foroutan Mirhosseini, Seyed Amid Tahami, Inge Hoff, Samer Dessouky, Chun-Hsing Ho, 2019. Performance evaluation of asphalt mixtures containing high-RAP binder content and bio-oil rejuvenator, Construction and Building Materials. doi.org/10.1016/j.conbuildmat.2019.07.191.

2. Hanaa Khaleel Alwan Al-Bayatia, Susan. Tighe, Jessica Achebe, 2018. Influence of recycled concrete aggregate on volumetric properties of hot mix asphalt. Journal homepage: www.elsevier.com/locate/resconrec. Resources, Conservation \& Recycling, 130 (2018) 200-214.

3. Hussein I. Abdel-Shafy and Mona S.M.Mansour., 2018. Solid waste issue: Sources, composition, disposal, recycling, and valorization. Egyptian Journal of Petroleum. Pages 427-1384. https://doi.org/10.1016/j.ejpe.2018.07.003.
4. Zainab Z. Ismail, Enas A. AL-Hashmi, (2007). Use of waste plastic in concrete mixture as aggregate replacement. ELSEVIER journal, Available online at www.sciencedirect.com, waste Management 28 (2008) 2041-2047.

5. Sunaryo, Marwan Efendy, Sarjito, Nur Saifullah. Kamarrudin. Pyrolysis of Plastic Waste as an Alternative Fuels in Spark Ignition Engine. International Journal of Emerging Trends in Engineering Research, Volume 7. No. 11, https://doi.org/10.30534/ijeter/2019/097112019.

6. Brian Prowell, (2008). Carbon Footprint: How Does HMA Stack Up?. Report used with Permission of the National Asphalt Pavement Association. Summer 2008.

7. Shahab HasaniNasaba, Mohsen Arast, Mohsen Zahedi, 2019. Investigating the healing capability of asphalt modified with nano-zycotherm and Forta fibers. Case Studies in Construction Materials. doi.org/10.1016/j.cscm.2019.e00235.

8. Zainab Z. Ismail, Enas A. AL-Hashmi, (2007). Use of waste plastic in concrete mixture as aggregate replacement. ELSEVIER journal, Available online at www.sciencedirect.com, waste Management 28 (2008) 2041-2047.

9. Aymen Awad, 2020. Guidelines for Civil Structures Demolition Method Selection to Enhance Environmental Protection. International Journal of Emerging Trends in Engineering Research, Volume 8. No. 2, https://doi.org/10.30534/ijeter/2020/11822020.

10. Aymen Awad and Feras Al adday, 2017. Utilization of waste plastics to enhance the performance of modified hot mix asphalt. International Journal of GEOMATE, Dec., 2017, Vol. 13, Issue 40, pp. 132-139. doi.org/10.21660/2017.40.170603.

11. Feras Al Adday, 2018. Eco-friendly hot mix asphalt by using recycled concrete aggregate and waste plastic. International Journal of Civil Engineering and Technology (IJCIET). Volume 9, Issue 7, July 2018, pp. 226-236, Article ID: IJCIET_09_07_023.

12. Rajdip Paul and Debashis Bhattacharya, 2015. Use of waste plastic in construction of road. Global journal of engineering science and researches, ISSN 2348 - 8034, Paul, 2(6), June 2015.

13. Miss Apurva $\mathbf{J}$ Chavan, 2013. Use of plastic waste in flexible pavements. International Journal of application or innovation in engineering and management (IJAEM). Volume 2, Issue 4.

14. Md. Nobinur Rahman, Mohammad Ahmeduzzaman, M. A. Sobhan and T. U. Ahmed, 2013. Performance Evaluation of Waste Polyethylene and PVC on Hot Asphalt Mixtures. American Journal of Civil Engineering and Architecture,2013, Vol. 1, No. 5, 97-102.

15. Ahmad M. Abu Abdo, 2017. Investigation the effects of adding waste plastic on asphalt mixes performance. Journal of Engineering and Applied Sciences. VOL. 12, NO. 15. 
Feras Al Adday et al., International Journal of Emerging Trends in Engineering Research, 8(4), April 2020, 1090 - 1095

16. Basim H. Al-Humeidawi, (2014). Utilization of Waste Plastic and Recycle Concrete Aggregate in Production of Hot Mix Asphalt. Al-Qadisiya Journal for Engineering Sciences, Vol. 7, No. 4. October 2014.

17. Aymen Awad, Firas Al Bajari and Feras Al Adday, 2019. A Case Study on Rainwater Harvesting and Reuse in Jordan. International Journal of Emerging Trends in Engineering Research Volume 7. No. 11, https://doi.org/10.30534/ijeter/2019/017112019.

18. Yadav Santosh, Saxena Anil Kumar, Arora T.R, (2013). Performance Evaluation of Waste Plastic and Bitumen Concrete mix in Flexible Pavements. International Journal of Scientific \& Engineering Research, Volume 4, Issue 10, ISSN 2229-5518, October 2013.

19. Esmaeil Ahmadinia, Majid Zargar, Mohamed Rehan Karim, Mahrez Abdelaziz, Payam Shafigh, 2011. Using waste plastic bottles as additive for stone mastic asphalt. Materials and Design, doi:10.1016/j.matdes.2011.06.016.

20. Rajib B. Mallick and Tahar El-Korchi, 2018. Pavement Engineering Principles and Practice. Third Edition, () 2018 by Taylor \& Francis Group, LLC. 